\title{
Portugal 2020 e o novo glossário do desenvolvimento territorial: territorialização ou neoinstitucionalização?
}

\author{
Portugal 2020 and the new glossary of territorial development: \\ territorialization or neo-institutionalization?
}

Filipe Ferreira, Paulo Castro Seixas

Universidade de Lisboa, Instituto Superior de Ciências Sociais e Políticas (ISCSP), Centro de Administração e Política Públicas (CAPP), Lisboa, Portugal

\section{Resumo}

Portugal encontra-se em um novo quadro comunitário (2014-2020) e político-administrativo, resultado do redesenho da arquitetura institucional que criou as entidades intermunicipais (Lei no $75 / 2013$ ). Tal contexto implica uma recente política territorial cujo objetivo é a territorialização das políticas em função de um novo glossário instrumental de desenvolvimento. Este artigo, por meio de uma revisão da literatura nacional e internacional, assim como da interpretação de alguns documentos estratégicos, faz o levantamento desse glossário do desenvolvimento, colocando em questão uma problemática: agendas abertas e participadas versus instrumentos de "código elaborado"; propósitos "inovadores" versus meios "ritualistas"; enfim, territorialização versus neoinstitucionalização das políticas públicas. Propõe-se, assim, em conclusão, que o novo quadro nacional, português e comunitário, encontra importantes limitações em função de políticas cujos objetivos/fins são territoriais e centrados nas pessoas, mas os instrumentos/meios são concebidos como institucionais e geridos por peritos. Tais conclusões colocam a governação multinível em questão, implicando um acompanhamento investigativo das relações ideal/real entre sociedade e estado e da distância entre participação esperada e real.

Palavras-chave: Política pública. Administração territorial. Desenvolvimento. Portugal 2020. Estratégia Europeia 2020.

\section{Abstract}

Portugal lives a new political and administrative framework, resulting both from the redesign of local administration architecture that generated the inter-municipal entities (Law 75/2013) and from the new European Community framework (2014-20). This context implies a new territorial policy aimed at the territorialization of policies and accordingly a new instrumental glossary of development. This paper, grounded on a national and international state of art and focusing on strategic documents, presents the new development glossary

FF é politólogo, mestre em Economia e Políticas Públicas, doutorando em Ciências Sociais - Especialidade em Desenvolvimento Socioeconómico, CAPP-ISCSP - Universidade de Lisboa, e-mail: filipe.emf@gmail.com

PCS é doutor em Antropologia Urbana, agregado em Sociologia Urbana, professor associado com Agregação, CAPP-ISCSP Universidade de Lisboa, e-mail: pseixas@iscsp.ulisboa.pt 
and a raises a problematic: the open and participatory agendas vs. the instruments in an "elaborated code"; the "innovative" purpose vs. the "ritualistic" means; in short the territorialization vs. the neo-institutionalization of public policies. We proposed, therefore, in conclusion, that the new Portuguese and European Community framework have important limitations since policies present goals/aims that are territorial and people-centered but with instruments/means which are designed as institutional and to be managed by experts. Such findings put multilevel government and governance in question, implying further research on ideal/real relations between society and state, and on the distance between expected and real participation.

Keywords: Public policy. Territorial administration. Development. Portugal 2020. Europe 2020.

\section{Introdução}

Em Portugal, existe desde 2013, um novo quadro comunitário e político-administrativo nacional, assim como uma recente política de desenvolvimento territorial, implicando um novo glossário instrumental. Essa mudança no cenário político-administrativo português decorre da introdução de legislação sobre a configuração das entidades intermunicipais ${ }^{1}$, ou seja, novas instituições que têm um papel relevante diante dos desafios que se colocam a Portugal para uma implementação eficaz do atual quadro comunitário, o qual se encontra plasmado no Acordo de Parceria Portugal 2014-2020 - é a tradução da Estratégia 2020 da União Europeia (Portugal, 2014). É nesse quadro duplo que a identificação das determinantes da eficácia das políticas públicas de desenvolvimento territorial constitui, simultaneamente, um desafio e uma necessidade. Ora, para a eficácia e o impacto desse quadro de desenvolvimento socioeconômico, certamente a amplitude dos parceiros capazes de pensar e dialogar essa estratégia será um dos indicadores de (in)sucesso. Esses são os pressupostos para a elaboração deste texto.

Este artigo concebe o território como "um elemento de governação das políticas públicas" (Reis, 2005, p. 25). Feio \& Chorincas (2009, p. 139), citando Reis (2007), referem que "[...] o território é um factor de racionalidade das políticas públicas,

\footnotetext{
${ }^{1}$ Estabelece o regime jurídico das autarquias locais, aprova o estatuto das entidades intermunicipais, determina o regime jurídico da transferência de competências do Estado para as autarquias locais e para as entidades intermunicipais, além de aprovar o regime jurídico do associativismo autárquico. Fonte: Lei ํㅜ 75, de 12 de setembro de 2013 (Portugal, 2013a).
}

sendo mais pertinente em políticas que dependem da proximidade e de relações finas com os contextos em que se inserem". Ora, apesar de implicar fortemente vários stakeholders, a verdade é que o novo glossário do desenvolvimento parece ser dominado, antes de mais nada, por peritos, especificamente policymakers e consultores. Assim, a partir de uma apresentação básica desse glossário, este texto interroga-se sobre a eficácia e o impacto possível de tal desenvolvimento sem que a democratização desse glossário faça parte da agenda da política em si mesma. Ou, de uma forma mais direta, como se pode falar de verdadeira territorialização das políticas públicas, se estas são feitas com uma linguagem e um pensamento só acessível a alguns?

As políticas centradas no território (place-based policies) coincidem grandemente com aquelas focalizadas nas pessoas (people-based policies) (Garcilazo et al., 2010). É nesse sentido que o código (linguagem) e a rede (parceria) em que tais políticas se desenvolvem são variáveis que não devem ser desprezadas. O Instituto Financeiro para o Desenvolvimento Regional $^{2}$ (Figueiredo et al., 2010, p. 11), no estudo de base que serviu de suporte para a preparação do

\footnotetext{
${ }^{2}$ O Instituto Financeiro para o Desenvolvimento Regional (IFDR) tem por missão dar execução à política de desenvolvimento regional por meio: da coordenação financeira dos fundos estruturais comunitários e do Fundo de Coesão (FC); da coordenação, gestão e monitorização financeira do Fundo Europeu de Desenvolvimento Regional (FEDER) e do FC; e do exercício das funções de pagamento e de controle das intervenções desses fundos. Fonte: Decreto de Lei no 137 , de 27 de abril de 2007 (Portugal, 2007). Em 2013, foi integrado à Agência para o Desenvolvimento e Coesão (AD\&C). Fonte: Decreto de Lei no 140, de 18 de outubro de 2013 (Portugal, 2013b).
} 
Territorial Survey da Organização para a Cooperação e Desenvolvimento Econômico (OCDE) sobre Portugal, ao se referir à problemática da territorialização das políticas, fala sobre a importância da

[...] concepção e implementação de programas e projetos com impacto territorial relevante, cujas prioridades são definidas em função de quadros estratégicos formulados para o território-alvo, com participação formal ou informal, na sua elaboração de instituições e atores identificados com tal território.

Também Feio \& Chorincas (2009, p. 137) consideram que esse tema da territorialização das políticas públicas é abordado em um contexto de crescente aumento da participação das instituições locais e regionais no funcionamento e na mudança dos sistemas econômicos e sociais, e que "[...] a territorialização das políticas públicas é encarada como fator-chave na gestão eficiente dos processos de desenvolvimento".

Assim, propõe-se que a territorialização das políticas e a gestão dos códigos (glossário) e das redes (parcerias) de tal proposta constituem-se como uma problemática. Uma agenda de desenvolvimento de participação alargada, portanto implicando uma abertura a vários "códigos restritos", apresenta-se, em paradoxo, no âmbito dos seus instrumentos de implementação em função de um "código elaborado" (Bernstein, 1971), gerido por um pequeno grupo de policymakers e consultores em uma rede fechada. Ou um modo de adaptação "inovador" na esfera dos propósitos conflitua com um modo de adaptação "ritualista" no campo da implementação (Merton, 1938). A efetividade e a eficácia das políticas públicas territoriais centrada nas pessoas são funções da linguagem (códigos) e da participação (participação). Assim, é nesse sentido que aqui invocamos, além de Robert Merton, Basil Bernstein, um sociólogo da linguagem que identificou dois tipos de códigos linguísticos que se confrontam no espaço de participação da interação de uma instituição (no caso, a escola): os códigos restritos, limitados a certos contextos sociais, e o código elaborado, dominante na escola e na sala de aula. Tais códigos cruzam atores e classes sociais, tornando a escola um lugar de tradução, fácil para uns, mas difícil para outros. A utilização de um "código elaborado" resulta em uma interação seletiva, com um "cliente ideal". Ora, o que se propõe aqui é que o desenvolvimento territorial que utilize um "código elaborado" vai resultar em uma participação seletiva e em um desenvolvimento de acordo com uma rede fechada e de um cliente ideal.

No caso de Merton, recorre-se à sua teoria dos modos de adaptação social (conformismo, ritualismo, inovação, rebelião, retraimento). Esse autor caracteriza os modos de adaptação social em função da orientação (positiva ou negativa) dos meios e dos fins. A proposta interpretativa aqui é que os objetivos da política propõem uma adaptação inovadora, em que os fins parecem mais importantes que os meios, mas logo os instrumentos de política parecem propor exatamente o contrário, um ritualismo, em um modo de adaptação social em que os meios são mais importantes que os fins.

Em suma, propõe-se como hipótese que a estratégia de desenvolvimento 2020 em Portugal pendula entre uma territorialização estratégica e uma neoinstitucionalização instrumental. Propõe-se, ainda, que essa problemática é central à própria política e sua gestão, criando dificuldades na eficácia e no impacto da territorialização das políticas que já se evidenciam.

Para a adequada contextualização e enquadramento estratégico dessa problemática importa assentar, em um primeiro momento, sobre a análise do processo de territorialização das políticas públicas na União Europeia para, em um segundo momento, perceber a tradução de tal estratégia para Portugal e, especificamente, os seus principais instrumentos. Metodologicamente, serão usados relatórios de organizações internacionais, como a União Europeia e a OCDE, para caracterizar os objetivos/fins da política, e, especificamente, o Acordo de Parceria Portugal 2014-2020, para evidenciar os instrumentos/meios de tal política, os quais, em um terceiro e último momento, que tais instrumentos/meios configuram um "código elaborado" em uma lógica de controle institucional forte, em paradoxo com uma agenda de desenvolvimento com objetivos/fins que requerem uma participação alargada forte. No entanto, esta é uma proposta de investigação que se apresenta de forma exploratória, pretendendo abrir uma linha de análise que posteriores enfoques sobre os instrumentos de política concretos e sua implementação poderão confirmar ou infirmar. 


\section{Da territorialização das políticas públicas na União Europeia: uma dualidade em processo}

Existem dois relatórios que evidenciam a mudança de paradigma para uma territorialização das políticas públicas no quadro europeu e internacional: o Relatório Barca - Uma Agenda para a Reforma da Política de Coesão (Barca, 2009) - e os relatórios da OCDE (2009) - How Regions Grow e Regions Matter: Economic Recovery, Innovation and Sustainable Growth -, ambos de 2009. No entanto, pode-se dizer mesmo que a territorialização das públicas na União Europeia é um desiderato de longo termo que, ao menos em parte, tem origem na própria formação da Comunidade Económica Europeia (CEE).

Condesso (2005), Fedajev \& Nikolic (2012), Santinha \& Marques (2012) e Santinha (2014) elencam a trajetória de territorialização de políticas públicas na União Europeia e afirmam que ela, desde a sua gênese), tem por missão a promoção de um desenvolvimento harmonioso das atividades econômicas por meio da redução das disparidades entre as diversas regiões.

Identificando a Política Regional Europeia como o instrumento de política mobilizado para cumprir a missão de desenvolvimento harmonioso, Esteban et al. (2009, p. 160) entendem que aquela foi concebida como uma política de solidariedade financeira orientada para a redução das disparidades econômicas e sociais entre regiões. Nessa linha de entendimento, os autores colocam um grande enfoque na natureza redistributiva dessa política, sendo as regiões menos desfavorecidas objeto de alocação de recursos que provinham das regiões mais desenvolvidas.

Relativamente à forma de implementação e pluralidade de instrumentos mobilizados,

Esta política, desarrollada de manera centralizada desde las distintas administraciones nacionales de la Comunidad, consistía en impulsar la industrialización en las regiones desfavorecidas a través de incentivos fiscales y financieros a las empresas para su localización en áreas predefinidas que deberían actuar como motores para el crecimiento económico (polos de desarrollo) (Esteban et al., 2009, p. 160).

A OCDE (2009, p. 50), no seu relatório Regions Matter: Economic Recovery, Innovation and Sustainable Growth, corrobora esse entendimento e focaliza a natureza redistributiva das transferências financeiras, que são acompanhadas pela existência de grandes programas de investimento público. No que concerne às limitações dessa política, a OCDE (2009, p. 50) enfatiza o confronto entre os objetivos da política regional dos anos de 1950 e 1960 e a sua incapacidade para fazer frente às questões que se levantaram nas décadas seguintes. De qualquer forma, a política redistributiva, de transferências financeiras e de apoio a regiões desfavorecidas sustentava-se em função da invenção de "corredores econômicos" fortes, mormente no centro da Europa, que pudessem criar spillovers.

Esteban et al. (2009, p. 169) mencionam que a crise de meados dos anos de 1970 e o longo processo de reestruturação econômica que se seguiu fizeram com que existisse uma revisão profunda dos objetivos, estratégias e instrumentos da Política Regional. Nessa sequência de alteração da realidade socioeconômica global e de revisão dos seus pressupostos, assiste-se a uma nova era na implementação das políticas regionais.

Assim,

The earlier focus on reducing disparities (in income, in infrastructure stock, etc.), was widened to include employment creation. The assumption was that public policy could alter supply conditions (essentially by changing production cost factors through production subsidies and incentives) and thereby influence industrial (re) location decisions for both existing firms and new investments (OCDE, 2009, p. 50).

Condesso (2005) refere que a União Europeia passou de um modelo de apoio às regiões menos desenvolvidas para uma visão coerente do território europeu diante das condições endógenas dos territórios nacionais. Essa dimensão territorial do processo de integração europeu favorece a articulação entre as instituições comunitárias e as políticas setoriais. Nesse contexto, a escala regional passou a ter uma importância acrescida na execução das políticas de desenvolvimento territorial, ao qual não foi alheia a adoção do princípio da subsidiariedade ${ }^{3}$ por parte da União Europeia.

\footnotetext{
${ }^{3}$ Princípio da subsidiariedade: aplicado ao contexto da União Europeia, serve de critério regulador do exercício das competências não exclusivas da União, cuja intervenção é excluída quando uma matéria pode ser regulamentada de modo eficaz pelos Estados-Membros em nível central, regional ou local, assim como confere legitimidade à União
} 
Santinha (2014), ao referenciar a trajetória europeia na direção de uma maior interligação entre a dimensão território e a formulação de políticas públicas, identifica a Agenda Territorial da União Europeia (CE, 2007), o Livro Verde sobre a Coesão Territorial (CE, 2008) e o Relatório Barca (2009) como marcos de referência na construção de uma nova abordagem europeia. Ainda para Santinha (2014), essa trajetória conduziu a um reconhecimento mais generalizado da importância da componente territorial para o projeto europeu, colocando nas agendas política e mediática essa temática, dando como exemplo a inclusão no Tratado de Lisboa do princípio da Coesão Territorial como o terceiro pilar da União Europeia (complementando os pilares da Coesão Econômica e Social).

Com a aprovação da Agenda Territorial da União Europeia 2020 durante a Reunião Informal de Ministros responsáveis pelo Desenvolvimento Territorial da União Europeia em 19 de maio de 2011, estabeleceu-se a necessidade da existência de políticas públicas que reforcem a importância da coesão territorial. Esse documento diz que o seu objetivo seria o de:

[...] providenciar orientações estratégicas para o desenvolvimento territorial, promover a integração da dimensão territorial dentro de diferentes políticas e a todos os níveis de governança e assegurar que a implementação da Estratégia Europa 2020 de acordo com os princípios da coesão territorial (UE, 2011, p. 4).

Segundo a Agenda Territorial da União Europeia (UE, 2011, p. 5), a melhor forma de se alcançar os resultados esperados na esfera da coesão territorial é a utilização das place-based policies, pois estas são fundamentadas em princípios de coordenação horizontal, em aplicação de políticas com base em evidências, no desenvolvimento funcional. Deriva desse entendimento que a operacionalização, no campo do policy making, do princípio da coesão territorial necessita de uma ancoragem e de um referencial estratégico especificamente definido.

No entanto, as limitações desse modelo também devem ser registradas. Essa visão estratégica territorial policêntrica pode bem ser vista como uma

para exercer os seus poderes quando os objetivos de uma ação não puderem ser realizados pelos Estados-Membros de modo satisfatório e a ação na esfera da União puder contribuir com valor acrescentado (2015 - Fichas Técnicas sobre a União Europeia (UE, 2015). compensação e, até mesmo, uma mitigação do processo de monocentrismo que a União Europeia foi construindo, ao centrar na área do Pentágono (área compreendida pela cidade de Londres, Paris, Milão, Hamburgo e Munique) cerca de 50\% do PIB europeu (Seixas, 2012). Assim, o policentrismo defendido pode ser entendido como ideológico (enquanto falsa consciência) ou como tentativa séria, mas tardia, de alteração de um quadro estratégico de privilégio do centro da Europa e ainda ativo. No entanto, há ainda que registrar que a visão top-down e bottom-up da competitividade e a coesão não coincidem necessariamente (Seixas, 2012, p. 170).

De qualquer forma, a territorialização das políticas públicas, ou place-based policies, tornou-se o paradigma a ser seguido, tendo como ponto de partida a necessidade de conhecer e explorar completamente o crescimento potencial de um território e de desenhar instituições e investimentos que não estão de momento disponíveis, mas que são produzidos por um processo deliberativo e participativo que envolva os atores locais e externos (Barca et al., 2012, p. 147). Dito de outra forma, em função de agendas e códigos abertos e de redes participadas, é possível inventar novas vantagens competitivas territoriais.

Para o relatório da OCDE Regional Outlook 2011: Building resilient regions for stronger economies (OCDE, 2011, p. 34), o racional para a nova abordagem regional é fundamentado no princípio de que existem oportunidades de crescimento em todos os territórios e em todos os tipos de regiões. Indo muito além do problema de como lidar com regiões mais atrasadas, 0 objetivo é maximizar a produção nacional, ajudando e incentivando cada uma delas a atingir o seu potencial de crescimento endógeno.

Barca et al. (2012, p. 147), corroborando essa análise, consideram que as place-based policies reconhecem os limites do Estado Central no desenho de boas políticas locais de desenvolvimento, enfatizando a necessidade de intervenção com base em parcerias entre diversos níveis de governança.

Todo esse processo de transição nas políticas da União Europeia evidencia reflexos de uma sobreposição de lógicas horizontalizadas e de redes às antigas lógicas verticalizadas e de centro-periferia na tradução das relações locais-globais, implicando também uma sobreposição de lógicas de participação e de governança às antigas lógicas institucionalistas. No entanto, o que se propõe aqui é que, se os objetivos/fins da 
política seguem uma lógica mais horizontal e de redes, sustentada em uma governação aberta à governança, a verdade é que os instrumentos surgem ainda relativamente fechados em uma "programação em cascata" verticalizada e relativamente institucional, ou melhor, neoinstitucional, descodificável por peritos e consultores.

\section{O ciclo de programação 2014-2020 em Portugal: o Portugal 2020}

Em Portugal, data de 2010 a obra que se apresenta como uma das primeiras a tratar do tema da territorialização das políticas públicas (Instituto Financeiro para o Desenvolvimento Regional - IFDR, 2010), tendo o quadro comunitário 2007-2013 já evidenciado em parte tal estratégia. 0 relatório “Territorialização das Políticas Públicas” (IFDR, 2010) tem o entendimento de que existe uma distinção entre a "territorialização de políticas públicas" e a existência de "impactos territoriais das políticas públicas". Nesse contexto, para que uma dada política pública possa ser considerada territorializada, não basta considerar que os investimentos ou as ações que a corporizam tenham um impacto territorial relevante. Relativamente ao atual período de programação comunitário (2014-2020) e, mais particularmente, à sua implementação em Portugal por meio do programa Portugal 2020, importa considerar que, segundo o Acordo de Parceria 2020 (Portugal, 2014, p. i), este

[...] adota os princípios de programação da Estratégia Europa 2020 e consagra a política de desenvolvimento económico, social, ambiental e territorial que estimulará o crescimento e a criação de emprego nos próximos anos em Portugal.

O Portugal 2020 é o Acordo de Parceria adotado entre o Estado Português e a Comissão Europeia, que reúne a atuação dos Fundos Europeus Estruturais e de Investimento (FEEI) ${ }^{4}$, no qual se definem os princípios de programação que consagram a política

\footnotetext{
${ }^{4}$ Fundos Europeus Estruturais e de Investimento (FEEI): Fundo Europeu de Desenvolvimento Regional (FEDER), Fundo Social Europeu (FSE), Fundo de Coesão (FC), Fundo Europeu Agrícola de Desenvolvimento Rural (FEADER), Fundo Europeu para os Assuntos Marítimos e Pescas (FEAMP). Fonte: UE (2013).
}

de desenvolvimento econômico, social e territorial a ser promovida em Portugal entre 2014 e 2020.

Esses princípios de programação estão alinhados com o crescimento inteligente, sustentável e inclusivo, prosseguindo a Estratégia Europa 2020, a qual representa "[...] uma visão da economia social de mercado para a Europa do século XXI [...]" (CE, 2010, p. 5) e pretende que a União Europeia se transforme em uma economia que mobilize três dimensões de crescimento (inteligente, sustentável e inclusivo) para que possam existir níveis elevados de emprego, produtividade e coesão social.

A programação do Portugal 2020, segundo o Acordo de Parceria 2020 (Portugal, 2014), organiza-se em quatro domínios temáticos: i) Competitividade e Internacionalização, ii) Inclusão Social e Emprego, iii) Capital Humano e iv) Sustentabilidade e Eficiência no Uso dos Recursos. Tais princípios são relevantes em dois domínios transversais: i) Reforma da Administração Pública e ii) Territorialização das Intervenções.

Relativamente à configuração das estruturas que operacionalizam o Portugal 2020, esta será efetuada por meio de 16 programas operacionais, acrescidos dos Programas de Cooperação Territorial nos quais Portugal participará a par com outros Estados-Membros (Figura 1).

\section{A dimensão territorial do Portugal 2020: um "código elaborado"}

No âmbito desta análise, mobiliza-se a dimensão territorial do Portugal 2020, referenciadas nas Abordagens Integradas de Desenvolvimento Territorial aí definidas, problematizando acerca dos fatores críticos de sucesso que possam contribuir para o êxito da sua implementação.

A centralidade dessas abordagens como meio de concretização das dimensões da Estratégia Europa 2020 é assumida pelo próprio Acordo de Parceria 2020 (Portugal, 2014, p. 241, grifo nosso):

Tomando em consideração a relevância atribuída pelo Tratado à dimensão territorial da Política de Coesão da União Europeia, e que as autoridades portuguesas consideram essencial no quadro da prossecução dos objetivos da Estratégia Europa 2020, as oportunidades propiciadas pelos regulamentos comunitários no âmbito das Abordagens Integradas de Desenvolvimento Territorial são significativamente valorizadas 


\begin{tabular}{|ll|}
\hline $\begin{array}{l}\text { Portugal } \\
2020\end{array}$ & 4 Programas Operacionais Temáticos no Continente \\
\cline { 2 - 2 } & 5 Programas Operacionais Regionais no Continente \\
& Programas Operacionais de Cooperação Territorial Europeia \\
\hline & 3 Programas de Desenvolvimento Rural \\
\hline & 1 Programa para o Fundo Europeu dos Assuntos Marítimos e das Pescas \\
\hline
\end{tabular}

Figura 1 - Estruturação operacional do Portugal 2020

Fonte: Elaboração própria.

e concretizadas em Portugal no período de programação 2014-2020 como dimensão essencial da promoção do crescimento inteligente, sustentável e inclusivo.

Nesse contexto de operacionalização das intervenções, o princípio da subsidiariedade, já referenciado, tal como identificado no Acordo de Parceria 2020, deverá afirmar-se como relevante no desenho e na estruturação dos instrumentos de programação de cariz territorial, no sentido em que potencializa o uso da escala territorial de intervenção como um dos mecanismos que imprimem maior racionalidade e eficiência na integração de políticas e na aplicação dos fundos comunitários.

As políticas públicas territoriais, em meio à aplicação de fundos comunitários, terão que estar alinhadas com a organização territorial do Estado. É nesse contexto que a existência de um novo referencial normativo que enquadra a organização político-administrativo do Estado Português na esfera territorial - Lei no $\mathbf{7 5 / 2 0 1 3}$ (Portugal, 2013a) ganha, assim, uma renovada pertinência e atualidade, fruto de um novo conjunto de competências e atribuições que robustecem a atuação das entidades intermunicipais (áreas metropolitanas e comunidades intermunicipais), nomeadamente no âmbito dos programas de desenvolvimento regionais e gestão dos fundos comunitários, bem como por meio da existência de um novo modelo de governação. Mas é exatamente por esse referencial normativo ser novo que as recém-criadas instituições, em uma fase do ciclo de vida organizacional dominada pela dualidade sobrevivência-consolidação e legitimada pelos códigos restritos dos instrumentos de políticas, podem reconsiderar o desiderato de territorialização das políticas em função de um neoinstitucionalismo.

O Acordo de Parceria 2020 (Portugal, 2014, p. 296), ao sublinhar a relevância e a pertinência das abordagens territoriais, identifica a escala NUTS III ${ }^{5}$ como o nível privilegiado para o estabelecimento de relações de coordenação e articulação entre os atores de diversos níveis territoriais. Como refere o Programa Operacional Centro 2020 (Programa Operacional da Região Centro, 2015), esse aproveitamento do capital territorial do país deve ser traduzido na utilização de instrumentos de programação que privilegiam as sub-regiões NUTS III como escala de intervenção, com o objetivo de mobilizar os diversos instrumentos de política a favor da prossecução de uma estratégia territorial coerente.

A existência dessas estratégias territoriais coerentes ganha corpo e expressão com a elaboração das Estratégias Integradas de Desenvolvimento Territorial (EIDT) por parte das entidades intermunicipais (áreas metropolitanas e comunidades intermunicipais), com a participação de inúmeros atores territoriais. Essa nova realidade trouxe consigo a introdução de um conjunto de novos instrumentos de política pública que

\footnotetext{
${ }^{5}$ Nomenclatura das Unidades Territoriais para Fins Estatísticos. Fonte: NUTS 2013: as novas unidades territoriais para fins estatísticos (INE, 2015) . Essas novas unidades, ao não terem uma identidade socioterritorial específica, enfatizam a lógica do neoinstitucionalismo.
} 
operacionalizam as EIDT, os quais são considerados aqui, de certo modo, como um "código elaborado", cuja abertura à participação dos diversos "códigos restritos" se abre como problemática a considerar.

O Programa Operacional Centro 2020 (Programa Operacional da Região Centro, 2015), no âmbito da implementação das EIDT, identifica os seguintes instrumentos:

- os Investimentos Territoriais Integrados (ITI), materializados por meio de Pactos para o Desenvolvimento e Coesão Territorial (PDCT);

- o Desenvolvimento Local de Base Comunitária (DLBC), materializado em Estratégias de Desenvolvimento Local (EDL);

- as Ações Integradas de Desenvolvimento Urbano Sustentável (AIDUS), fundamentadas em um eixo autônomo dos programas operacionais regionais.

\section{Investimentos Territoriais Integrados (ITI)}

Regio (2015, p. 6) diz que:

Integrated Territorial Investment (ITI) is a new tool introduced in the Common Provision Regulation (CPR) for use during the European Structural and Investment Funds (ESIF) programming period. Its aim is to make it easier to run territorial strategies that need funding from different sources. ITI also promotes a more local or 'place-based' form of policy making.

Em um contexto de implementação desse instrumento em Portugal, é referenciado que:

No quadro da prossecução dos objetivos da Estratégia Europa 2020, visando a promoção do crescimento inteligente, sustentável e inclusivo, os Investimentos Territoriais Integrados (ITI) serão concretizados através de Pactos para o Desenvolvimento e Coesão Territorial, ancoradas nas estratégias de desenvolvimento territorial acima referidas (Portugal, 2014, p. 306).

Segundo o Centro 2020 (Programa Operacional da Região Centro, 2015), os ITI terão por base estratégias de desenvolvimento territorial as quais servirão de referência para assegurar a coerência estratégica de outras intervenções de cariz local e que, dessa forma, é pretendida a criação de um quadro estratégico sub-regional completo e claro, articulado com a estratégia regional e que possa garantir a coerência das intervenções, independentemente da forma como são implementadas.

No que se refere ao enquadramento financeiro, no Acordo de Parceria 2020 (Portugal, 2014, p. 306), menciona-se que os PDCT poderão ser financiados pelo FEDER, FSE, FC e FEADER e incluir tipologias distintas de subsídios reembolsáveis e não reembolsáveis, bem como ser articulados com outros instrumentos financeiros.

Na dimensão dos objetivos e desafios, no Acordo de Parceria 2020 (Portugal, 2014, p. 301), é dito que estes se sitiam no:

Desenvolvimento de estratégias de baixo carbono, de prevenção e gestão de riscos e de proteção do ambiente e a adaptação às alterações climáticas; b) Estruturação do sistema urbano nacional (incluindo a reorganização, a gestão em rede e o aumento da qualidade de prestação dos serviços públicos e coletivos); c) modernização da administração pública local; d) promoção do emprego (sustentável e com qualidade) e e) reforço da coesão e inclusão social.

\section{Desenvolvimento Local de Base Comunitária (DLBC)}

O instrumento de política DLBC, na sua atual designação, é uma inovação do ciclo de programação 2014-2020, mas tem as suas origens na iniciativa LEADER, tendo a sua metodologia e abordagem que servem para programas e iniciativas comunitárias como o URBAN ${ }^{6}$ e o EQUAL.

Como trata a Comissão Europeia (CE, 2014, p. 2):

Over the past 20 years, the LEADER approach' to community-led local development (CLLD), financed by the Structural and the Rural Development

\footnotetext{
${ }^{6}$ Iniciativa Comunitária URBAN (2000-2006): tinha como objetivo apoiar a revitalização e a requalificação das áreas urbanas - centros de cidades e suas periferias - com fortes sinais de depressão e degradação, com problemas de declínio econômico e urbano, desemprego e deterioração da qualidade de vida e acumulação de fenômenos de exclusão social e insegurança.
} 
Funds, has helped rural actors consider the longterm potential of their local region, and proven an effective and efficient tool in the delivery of development policies. The European Commission has promoted this delivery method also through Community Initiatives URBAN and EQUAL7.

No atual ciclo de programação comunitária, o instrumento de política DLBC pode ser definido como:

CLLD is a specific tool for use at sub-regional level, which is complementary to other development support at local level. CLLD can mobilise and involve local communities and organisations to contribute to achieving the Europe 2020 Strategy goals of smart, sustainable and inclusive growth, fostering territorial cohesion and reaching specific policy objectives (CE, 2014, p. 2).

Em um contexto de implementação em âmbito nacional e quanto aos objetivos, o Acordo de Parceria 2020 (Portugal, 2014) e o Centro 2020 (Programa Operacional da Região Centro, 2015) tratam sobre a existência de uma mobilização para estimular o desenvolvimento local em territórios específicos, diversificar as economias de base rural e das zonas pesqueiras e costeiras e, complementarmente, promover a inovação social, por meio de respostas a problemas de pobreza e de exclusão social, designadamente em territórios economicamente fragilizados e/ou de baixa densidade populacional.

Os mesmos autores dizem ainda que esse instrumento também tem como objetivos o apoio a iniciativas integradas de promoção da inclusão social, com ênfase no empreendedorismo social, de combate à pobreza e ao abandono escolar em territórios urbanos desfavorecidos dos centros urbano de nível superior.

No Centro 2020 (Programa Operacional da Região Centro, 2015, p. 9), as DLBC são aprovadas com base em um processo de seleção concorrencial envolvendo Grupos de Ação Local (GAL), que terão de apresentar EDL e os correspondentes programas de ação para três tipologias distintas de territórios: i) comunidades de base rural, com população entre 10 mil e 150 mil habitantes, referentes às áreas de atuação dos GAL Rurais; ii) comunidades pesqueiras

\footnotetext{
${ }^{7}$ Iniciativa Comunitária EQUAL (2000-2006): tinha como objetivo a eliminação dos fatores que estão na origem das desigualdades e discriminações no acesso ao mercado de trabalho.
}

e costeiras, com população entre $10 \mathrm{mil}$ e $200 \mathrm{mil}$ habitantes, correspondentes às áreas de atuação dos atuais GAL Costeiros; iii) comunidades de base urbana, que são territórios urbanos desfavorecidos, com população entre 10 mil e 150 mil habitantes.

\section{Ações Integradas de Desenvolvimento Urbano Sustentável (AIDUS)}

Segundo o Acordo de Parceria 2020 (Portugal, 2014, p. 311), Ações Integradas de Desenvolvimento Urbano Sustentado destinam-se a prosseguir estratégias de desenvolvimento sustentável, tendo em consideração a relevância dos sistemas urbanos na dinamização do crescimento e do emprego, da competitividade e da inovação, e também da sustentabilidade e promoção da qualidade de vida.

Para o Centro 2020 (Programa Operacional da Região Centro, 2015, p. 13), esse instrumento busca a valorização da estruturação urbana dos territórios de incidência e a promoção da atratividade e da competitividade das cidades.

É importante considerar (Programa Operacional da Região Centro, 2015, p. 13) que os Planos Estratégicos de Desenvolvimento Urbano (PEDU):

[...] são selecionados em função de princípios de seleção comuns que ponderam a proporcionalidade do investimento proposto, a capacidade administrativa das autoridades urbanas, as características sócio funcionais do espaço a intervir, a coerência e articulação das intervenções previstas com outros instrumentos de promoção da revitalização urbana, e assegurem uma dimensão crítica que permita a obtenção de impactes relevantes da intervenção na redensificação da população urbana e no desenvolvimento urbano sustentável, em matéria de qualidade ambiental e urbanística.

Para implementação da estratégia, deverão estar definidos três tipologias distintas de planos que tenham como grupo-alvo as autoridades urbanas dos centros urbanos das Áreas Metropolitanas de Lisboa e Porto, bem como os centros urbanos de nível superior do Programa Nacional da Política de Ordenamento do 
Território (PNPOT) ${ }^{8}$ e dos Programas Regionais de Ordenamento do Território (PROT) ${ }^{9}$ :

- o plano de mobilidade urbana sustentável no âmbito de NUT III;

- o plano de ação para a regeneração urbana em áreas específicas selecionadas, áreas de reabilitação urbana (ARU), em concreto, centros históricos, zonas ribeirinhas ou zonas de conversão de zonas industriais abandonadas;

- o plano de ação integrado para o caso de comunidades desfavorecidas objeto de intervenção.

\section{Conclusões: territorialização ou neoinstitucionalização?}

O novo quadro comunitário e político-administrativo nacional evidencia uma política de territorialização das políticas públicas, mas que tem de ser implementada em função de instrumentos de desenvolvimentos muito específicos. Diante dessa problemática, a interpretação proposta é a de que o novo quadro nacional português e comunitário encontra importantes limitações de acordo com políticas cujos objetivos/fins são territoriais e centrados nas pessoas, mas os instrumentos/meios são concebidos como institucionais e geridos por peritos. Em outras palavras, uma política que objetiva revelar uma reflexividade das teorias centradas na sociedade, a qual é concebida como uma variável dependente do Estado da sociedade e é o contexto central das políticas públicas, mas que, no âmbito dos instrumentos/meios, revela-se devedora de uma

\footnotetext{
${ }^{8}$ O Programa Nacional da Politica de Ordenamento do Território (PNPOT) é um instrumento de desenvolvimento territorial de natureza estratégica que estabelece as grandes opções com relevância para a organização do território nacional, consubstancia o quadro de referência a considerar na elaboração dos demais instrumentos de gestão territorial e constitui um instrumento de cooperação com os demais Estados-Membros para a organização do território da União Europeia (D. G. Território, 2014).

${ }^{9}$ Os Programas Regionais de Ordenamento do Território (PROT) definem a estratégia regional de desenvolvimento territorial, integrando as opções estabelecidas na esfera nacional e considerando as estratégias sub-regionais e municipais de desenvolvimento local, constituindo o quadro de referência para a elaboração dos programas e dos planos intermunicipais e municipais (Portugal, 2015).
}

perspectiva estatal das políticas públicas, fortemente institucionalista e dominada por peritos.

A complexidade crescente da realidade do policy making da União Europeia e de Portugal é um fenômeno social de elevada pertinência, sendo a sua investigação atual e relevante, em uma lógica de aprofundamento científico e de problematização de questões de elevado impacto social. A implementação do Programa Portugal 2020, no contexto da Política de Coesão da União Europeia para o Ciclo de Programação 2014-2020, nomeadamente na sua vertente territorial, deve ser objeto de reflexão e de problematização por parte da comunidade científica.

Várias agendas políticas internacionais parecem cada vez mais indicar a territorialização (place-based policies e people-based policies) e a participação (governance) como avenidas a percorrer. No entanto, talvez valha a pena distinguir os vários tipos de territorialização das políticas (impactos territoriais de políticas setoriais; territorialização de políticas setoriais; políticas de base territorial) e os vários tipos de participação do cidadão (desde a não participação ao tokenismo e ao poder cidadão). A famosa escada de Arnstein da participação (Arnstein, 1969) deve correlacionar-se com uma escada de territorialização.

Neste texto, foram problematizadas a territorialização e a participação em função dos conceitos de "código" e de "rede". Foi proposto que o código (linguagem) e a rede (parceria) são variáveis fundamentais da análise da efetividade e eficácia das políticas territoriais no seu sentido estrito. Considerou-se, mesmo como hipótese a explorar, que as políticas territoriais, em função da utilização de tal "código elaborado" e de uma "rede fechada", desmentiam os seus objetivos pelos meios mobilizados para atingi-los, os quais eram, antes, a evidência de um neoinstitucionalismo. Ao longo da exposição, foram considerados vários argumentos em favor dessa hipótese que se tenta, a seguir, sistematizar como argumentos do neoinstitucionalismo:

1. um novo glossário do desenvolvimento territorial estabelecido de forma top-down (a chamada "programação em cascata");

2. a ausência de um verdadeiro esforço de divulgação/ democratização de tal glossário, constituindo-se como um "código elaborado";

3. o dominío de tal "código elaborado" por parte de uma rede fechada de peritos e policymakers; 


\section{Quadro 1 - Territorialização ou neoinstitucionalização}

\begin{tabular}{|c|c|}
\hline Territorialização & Neoinstitucionalização \\
\hline Centrado no território & Centrado no glossário \\
\hline Centrado nas pessoas & Centrado nas possibilidades políticas \\
\hline Centrado em territórios concretos & Centrado em territórios político-estatísticos \\
\hline Gerido pela participação & Gerido por políticos e peritos \\
\hline Gerido de forma multinivel & Gerido de cima para baixo ("cascata") \\
\hline Gerido para a inovaç̦ão & Gerido pelo ritualismo \\
\hline Desenvolvimento para todos & Desenvolvimento de cliente ideal \\
\hline Desenvolvimento de resposta territorial & Desenvolvimento tipificado \\
\hline Desenvolvimento mobilizador & Desenvolvimento reprodutor \\
\hline
\end{tabular}

Fonte: Elaboração própria.

4. a identificação de novas entidades territoriais (NUTS III) como destinatários dos fundos, sendo definidas de forma estatística, e não como identidades socioterritoriais específicas;

5. a criação de novas entidades territoriais gestoras dos fundos (entidades intermunicipais), elas próprias sem uma identidade socioterritorial definida.

Esses argumentos elencados resultam em um paradoxo entre os objetivos das políticas territoriais e os meios efetivos para levá-las a cabo, propondo-se que aos objetivos inovadores de políticas territoriais efetivamente place and people-based se sobrepõem os meios de tipo ritualista, ou seja, que apenas seguem a lógica do manual (Acordo de Parceria) e das suas possibilidades políticas. Propôs-se, por fim, que o acompanhamento dos EIDT (ITI, PDCT, DLBC, EDL e AIDUS), em termos de investigação, poderia confirmar (ou infirmar) a hipótese apresentada de que as políticas territoriais ficaram subjugadas por um quadro neoinstitucional de "códigos elaborados" (periciais) inteligíveis apenas no quadro de uma "rede fechada" de policymakers e consultores e no qual a participação se reduziu a uma mera consulta assistemática.

No Quadro 1, procura-se esboçar os resultados da análise efetuada, propondo um modelo de territorialização versus um modelo de neoinstitucionalização como hipótese para a compreensão do quadro de desenvolvimento 2014-2020 em Portugal.
Na primeira metade de $2016^{10}$, mais especificamente em abril, foi aprovado o Plano Nacional de Reformas Portugal 2020 pelo Conselho de Ministros. Glosando os jornais da época, "[...] cerca de metade dos fundos comunitários disponíveis no Portugal 2020 são absorvidos pelo Plano Nacional de Reformas"11, ao mesmo tempo que "o dinheiro ainda não chegou aos municípios". Ora, em si mesma tal situação não parece sustentar uma verdadeira territorialização das políticas. Ouve-se também dizer que "o dinheiro é pouco para cada município e a distribuir por vários anos", ou, no caso de possíveis investimentos privados, que "é preferível os empréstimos em bancos do que candidaturas aos fundos". Em outras palavras, a estratégia de territorialização (place-based e people-based policies) das políticas pode ser compreendida como uma espécie de flirt, motivando os vários stakeholders para a chegada dos fundos comunitários ou para uma participação de sua gestão. No entanto, os instrumentos de implementação de tal política parecem até agora

${ }^{10}$ Este texto foi terminado na primeira semana de junho de
2016.
${ }^{11}$ No Jornal Observador (2016) afirma-se: “Após esta sessão de
lançamento a cargo de António Costa, o Programa Nacional de
Reformas será depois, durante as próximas semanas, objeto
de discussão pública, envolvendo partidos e a concertação
social, antes de ser entregue pelo Governo português em
Bruxelas. Em declarações à agência Lusa, o ministro do
Planeamento e das Infraestruturas, Pedro Marques, disse
que o executivo pretende alocar nos próximos cinco anos
'cerca de metade dos fundos comunitários disponíveis no
Portugal 2020', ou seja, 'entre 10 a 11 mil milhões de euros'”. 
ter sido grandemente dominados pelo Estado, pelas suas novas lógicas institucionais e por think thanks de policymakers e consultores.

Assim, essa problemática entre expectativa e efetiva participação, entre territorialização e neoinstitucionalização, entre objetivos abertos a códigos restritos, mas geridos por um código elaborado, e em função de uma rede fechada, ou ainda entre um modo de adaptação centrado na inovação/empreendedorismo de propostas e um ritualismo instrumental, propõe-se como linha de investigação para o acompanhamento da implementação do conjunto de novos instrumentos de política (ITI, DLBC e AIDUS) em Portugal. Esses novos instrumentos que corporizam todo um novo glossário do desenvolvimento territorial, pela sua novidade temática e pelo recurso a um novo conjunto de possibilidades de financiamento, impõem uma agenda de investigação de natureza interdisciplinar e crítica, atenta às relações ideal/real entre sociedade e Estado como suporte de políticas públicas.

A área cientifica das políticas públicas, pela sua natureza agregadora de diversas disciplinas, pode oferecer um enquadramento científico capaz de responder às necessidades metodológicas dessas linhas de investigação, bem como ter uma função de analysis of policy que poderá e deverá trazer valor acrescentado aos policymakers nacionais.

\section{Referências}

Arnstein, S. R. (1969). A ladder of citizen participation. Journal of the American Planning Association, 35(4), 216-224.

Barca, F. (2009). Relatório Barca - Uma Agenda para a Reforma da Política de Coesão. Bruxelas: Comissão Europeia.

Barca, F., McCann, P., \& Rodríguez-Pose, A. (2012). The case for regional development intervention: place-based versus place-neutral approaches. Journal of Regional Science, 52(1), 134-152. http://dx.doi.org/10.1111/j.1467-9787.2011.00756.x.

Bernstein, B. (1971). Class, codes and control: theoretical studies towards a sociology of language. London: Routledge \& Kegan Paul.

Comissão Europeia - CE. (2007). Agenda Territorial da União Europeia. Leipzig: CE. Reunião Informal dos Ministros do Desenvolvimento Urbano e Coesão Territorial, Presidência Alemã da UE.
Comissão Europeia - CE. (2008). Livro Verde sobre a Coesão Territorial Europeia - Tirar Partido da Diversidade Territorial. Bruxelas: CE. Comunicação da Comissão ao Conselho, ao Parlamento Europeu, ao Comité das Regiões e ao Comité Económico e Social Europeu, COM(2008) 616 final.

Comissão Europeia - CE. (2010). EUROPA 2020: estratégia para um crescimento inteligente, sustentável e inclusivo. Bruxelas: UE.

Comissão Europeia - CE. (2014). Community-led local development. Bruxelas: Cohesion Policy.

Condesso, F. D. (2005). Ordenamento do território. Lisboa: Instituto Superior de Ciências Sociais e Políticas.

D. G. Território. (2014, 28 de outubro). Programa Nacional da Politica de Ordenamento do Território. Lisboa: Direção-Geral do Território. Recuperado em 4 de setembro de 2016, de http://www.dgterritorio.pt/ordenamento_e_cidades/ ordenamento_do_territorio/pnpot/

Esteban, M., Rodriguez, A., Moreno, J., \& Altuzarra, A. (2009). La evaluación de la Política Regional Europea. Análisis empírico de las metodologías aplicadas. Investigaciones Regionales, 14, 157-184.

Fedajev, A., \& Nikolic, R. (2012). The concepts, methods and measurement of EU regional development. Economics Management Information Technology, 1(1), 48-57.

Feio, P. A., \& Chorincas, J. (2009). Governação territorial e inovação das políticas públicas. Prospectiva e Planeamento, 16, 137-157.

Figueiredo, A. M., Leal, I., \& Meireles, R. (2010). $A$ Territorialização das Políticas Públicas em Portugal. Lisboa: IFDR - Instituto Financeiro para o Desenvolvimento Regional.

Garcilazo, J. E., Martins, J. O., \& Thompson, W. (2010). Why policies may need to be place-based in order to be people-centred. Recuperado em 24 de maio de 2016, de http://voxeu.org/article/ why-policies-may-need-be-place-based-order-be-people-centred Instituto Financeiro para o Desenvolvimento Regional IFDR. (2010). A Territorialização das Políticas Públicas em Portugal. Lisboa: IFDR.

Instituto Nacional de Estatística - INE. (2015). NUTS 2013 - As novas unidades territoriais para fins estatísticos. Lisboa: INE.

Jornal Observador. (2016, 29 de março). Lisboa, Agência Lusa. 
Merton, R. K. (1938). Social structure and anomie. American Sociological Review, 3(5), 672-682. http://dx.doi. org/10.2307/2084686.

Organização para a Cooperação e Desenvolvimento Econômico - OCDE. (2009). Regions matter: economic recovery, innovation and sustainable growth. Paris: OECD Publishing.

Organização para a Cooperação e Desenvolvimento Econômico - OCDE. (2011). Regional outlook 2011: building resilient regions for stronger economies. Paris: OECD Publishing.

Portugal. Ministério do Ambiente, do Ordenamento do Território e do Desenvolvimento Regional. (2007, 27 de abril). Decreto de Lei n. ${ }^{o}$ 137/2007 de 27 de Abril. Lisboa: Diário da República, série I.

Portugal. Assembleia da República. (2013a, 13 de setembro). Lei $n^{\circ}$ 75/2013 de 12 de setembro. Estabelece o regime jurídico das autarquias locais, aprova o estatuto das entidades intermunicipais, estabelece o regime jurídico da transferência de competências do Estado para as autarquias locais e para as entidades intermunicipais e aprova o regime jurídico do associativismo autárquico. Lisboa: Diário da República, 1.르 série, ‥o 176.

Portugal. Presidência do Conselho de Ministros. (2013b, 18 de outubro). Decreto de Lei n.ํㅜ 140/2013 de 18 de outubro. Lisboa: Diário da República, n.o 202, série I.

Portugal. (2014). Acordo de Parceria Portugal 2014-2020. Lisboa: Governo de Portugal.

Portugal. Ministério do Ambiente, do Ordenamento do Território e do Desenvolvimento Regional. (2015, 27 de maio). Decreto de Lei n.o 80/2015 de 14 de maio. Lisboa: Diário da República, n.. 93, série I.

Programa Operacional da Região Centro. (2015). Abordagens territoriais: uma análise aplicada ao Programa Operacional Regional do Centro 2014-2020. Coimbra: Programa Operacional da Região Centro.

Regio D. G. (2015). Scenarios for integrated territorial investments. Bruxelas: European Comission.
Reis, J. (2005). Governação regional e gestão das intervenções financiadas pelos fundos estruturais, Estudo para o Observatório do QCAIII. Coimbra: FEUC.

Santinha, G. (2014). 0 princípio de coesão territorial enquanto novo paradigma de desenvolvimento na formulação de políticas públicas: (re)construindo ideias dominantes. EURE, 40(119), 75-97. http://dx.doi.org/10.4067/ S0250-71612014000100004.

Santinha, G., \& Marques, J. (2012). A integração do princípio de Coesão Territorial na agenda política: o caso português. Revista de Geografia e Ordenamento do Território, 2, 215-244.

Seixas, P. C. (2012). Políticas e modelos de desenvolvimento territorial na Europa e em Portugal. Revista Paranaense de Desenvolvimento, 122, 147-175.

União Europeia - UE. (2011). Agenda Territorial da União Europeia para 2020. Godollo, Hungria: UE. Documento aprovado durante a Reunião Informal de Ministros responsáveis pelo Desenvolvimento Territorial da União Europeia, A19 de Maio 2011.

União Europeia - UE. (2013, 17 de dezembro). Regulamento (UE) n.o 1303/2013 do Parlamento Europeu e do Conselho de 17 de dezembro de 2013, que estabelece disposições comuns relativas ao Fundo Europeu de Desenvolvimento Regional, ao Fundo Social Europeu, ao Fundo de Coesão, ao Fundo Europeu Agrícola de Desenvolvimento Rural e ao Fundo Europeu dos Assuntos Marítimos e das Pescas, que estabelece disposições gerais relativas ao Fundo Europeu de Desenvolvimento Regional, ao Fundo Social Europeu, ao Fundo de Coesão e ao Fundo Europeu dos Assuntos Marítimos e das Pescas, e que revoga o Regulamento (CE) n.o 1083/2006 do Conselho. Bruxelas: Jornal Oficial da União Europeia, L347.

União Europeia - UE. (2015). 2015 - Fichas Técnicas sobre a União Europeia. Recuperado em 24 de maio de 2016, de http://www.europarl.europa.eu/ftu/pdf/pt/FTU_1.2.2.pdf

Recebido: Jun. 05, 2016

Aprovado: Out. 18, 2016 